\title{
O MITO DA OUTORGA E A ATUAL LEGISLAÇÃO TRABALHISTA NO BRASIL
}

\section{THE MYTH OF GRANTING AND CURRENT LABOR LAW IN BRAZIL}

\author{
Amauri Cesar Alves* \\ Marina Souza Lima Rocha**
}

\begin{abstract}
Resumo
O presente artigo pretende debater a inconsistência do mito da outorga varguista e demonstrar que a Consolidação das Leis do Trabalho, em 1943, é fruto da pressão dos trabalhadores sobre o capital e o Estado e que esse instrumento normativo vem sendo vilipendiado pelo Estado neoliberal brasileiro, principalmente, a partir de 2017. A construção teórica se dá principalmente em torno da doutrina de Direito do Trabalho e da História, mas conta também com aportes das Ciências Sociais/Sociologia. O objetivo é demonstrar que a legislação trabalhista é fruto de conquistas sociais importantes e que, também por isso, deveria ser protegida. A conclusão é que o Direito do Trabalho cumpriu historicamente uma função de equilíbrio entre capital e trabalho, e sua destruição certamente trará impactos negativos para o sistema, com consequências que poderão ser graves para todos os envolvidos.

Palavras-chave: Mito da outorga. Getúlio Vargas. Direito do Trabalho. Crise.
\end{abstract}

\begin{abstract}
The present article intends to debate the inconsistency of the Getúlio Vargas "Myth of Granting" and demonstrate that the Consolidation of Labor Laws in 1943 is the result of the pressure of workers on capital and the State and that this normative instrument has been vilified by the Brazilian neo-liberal State, especially from 2017 onwards. The theoretical construction takes place mainly around the doctrine of Labor Law and History, but also includes contributions from Social Sciences/Sociology. The objective is to demonstrate that labor legislation is the result of important social achievements and that, for this reason, it should be protected. The conclusion is that Labor Law has historically fulfilled a function of balancing capital and labor, and its destruction will certainly have negative impacts on the system, with consequences that could be serious for all those involved.
\end{abstract}

Keywords: Myth of Grant. Getúlio Vargas. Labor Law. Crisis.

\section{Introdução}

O presente artigo pretende debater a inconsistência do mito da outorga varguista e demonstrar que a Consolidação das Leis do Trabalho, em 1943, é fruto da pressão dos trabalhadores sobre o capital e o Estado, que responderam com a consagração de direitos mínimos para a classe trabalhadora. A ideia é afirmar a preponderância dos trabalhadores na construção

\footnotetext{
* Doutor, mestre e bacharel em Direito pela PUC Minas. Professor (Graduação e Mestrado) da Universidade Federal de Ouro Preto. Coordenador do Grupo de Estudos de Direito do Trabalho da UFOP. Avaliador de cursos de Graduação em Direito, INEP/MEC. Email: amauri.alves.dte@gmail.com

** Bacharela em Direito pela Universidade Federal de Ouro Preto (UFOP), mestranda e bolsista no Programa de Pós-Graduação em Direito da Universidade Federal de Ouro Preto (PPGD-UFOP), integrante do Grupo de Estudos de Direito do Trabalho da UFOP. E-mail: marinarocha.direito@gmail.com
} 
de direitos trabalhistas e denunciar a perda de direitos promovida pelo Estado brasileiro desde 2017, o que deve gerar a repulsa da classe trabalhadora, que afinal conquistou os direitos que agora são afetados por políticas neoliberais. A construção teórica se dá principalmente em torno da doutrina de Direito do Trabalho, da História e da Sociologia.

O artigo parte de problemas concretos: a legislação trabalhista é fruto de uma dádiva estatal, ou, mais precisamente, da outorga de Getúlio Vargas, ou é decorrente, dentre outros fatores, da luta da classe trabalhadora por direitos mínimos? As alterações legislativas havidas no Brasil pós-2017 significam destruição do patamar civilizatório de direitos trabalhistas? A ideia é relacionar conquistas normativas históricas e a atual perda de direitos trabalhistas, para chamar a atenção para a atuação do Estado neoliberal brasileiro dos dias de hoje.

Para que seja possível concretizar o que está proposto o artigo se estrutura em dois itens principais. O primeiro busca retomar o debate justrabalhista em torno do mito da outorga, para demonstrar suas origens, seus fundamentos e sua imprecisão. O segundo demonstra a atual destruição do Direito do Trabalho, fruto de ideário neoliberal implementado pelo governo Michel Temer e que segue seu curso no governo Bolsonaro. O objetivo é demonstrar que a legislação trabalhista é fruto de conquistas sociais históricas e que, também por isso, não deveria ser precarizada. A conclusão é que o Direito do Trabalho cumpriu historicamente uma função de equilíbrio entre capital e trabalho e sua destruição trará impactos negativos para o sistema.

\section{História do Direito do Trabalho no Brasil: a Era Vargas e a Consolidação das Leis do Trabalho}

O período em que o poder executivo em âmbito nacional foi ocupado por Getúlio Vargas foi marcado por inúmeras inovações no modo de se fazer política. Seja qual for a visão adotada sobre Getúlio, não há como negar a sua popularidade e protagonismo no cenário político nacional. A relevância de Vargas para o Direito do Trabalho brasileiro também é inegável, vistos, exemplificativamente, os atuais debates pela preservação ou não de seu principal ponto de sustentação junto à classe trabalhadora de sua época, a Consolidação das Leis do Trabalho (CLT). A luta da classe trabalhadora por direitos, entretanto, é anterior ao governo Vargas e não se esgota com ele.

Antecedentes históricos ao varguismo e a luta dos trabalhadores pela consagração de direitos

Analisar o nascimento e as transformações do direito do trabalho no Brasil, bem como das formas de organização da classe trabalhadora (dentre elas o sindicalismo) pressupõe uma reflexão, mesmo que superficial, de um triste período da história marcado pela escassez de direitos trabalhistas e de trabalho assalariado: a escravidão.

O período escravocrata durou de aproximadamente 1550 até 1888, com a abolição formal e juridicamente prevista pela Lei Áurea, mas ecoam graves e inúmeras consequências 
até os dias de hoje no Brasil. Tal fase da conturbada história brasileira foi marcada pelo racismo e pela utilização exaustiva de mão de obra, tendo como contraprestação castigos, maus-tratos e discriminação. Pessoas escravizadas trabalhavam, mas não tinham direitos trabalhistas, não recebiam salários e não tinham sequer reconhecimento jurídico como seres humanos. Porém uma coisa nunca lhes faltou: resistência.

Após mais de 300 anos de regime escravista, adveio o fim da escravidão, motivado por movimentos de resistência de pessoas escravizadas - que fundaram quilombos, quebraram instrumentos de trabalho e até as próprias senzalas (FAUSTO, 1995) -, por lutas abolicionistas e pela necessidade de modificação das relações de trabalho para se adaptar ao capitalismo industrial (ALVES, 2015). As formas de trabalho assalariado foram, em consequência disso, ganhando espaço e se consolidando no país. A abolição da escravidão, em 1888, "é referência histórica para as relações de trabalho no Brasil, visto que somente então se tornou possível o trabalho livre como hegemônico" (ALVES, 2015, p. 19).

Nos últimos anos do Império e nos primeiros anos da República começou a se desenvolver a nascente atividade industrial nas áreas urbanas, especificamente no Rio de Janeiro e em São Paulo. Financiada pelos lucros provenientes do café e contando com grande contingente de mão de obra estrangeira, a atividade industrial fez nascer a incipiente classe trabalhadora urbana no Brasil (FAUSTO, 2006).

As condições de trabalho nas indústrias eram degradantes, os salários baixos e as jornadas elevadas. Os trabalhadores quase não tinham direitos trabalhistas e o custo de vida nas cidades se mostrava demasiadamente alto. Também em razão disso, "desde o início da Primeira República surgiram expressões da organização e mobilização dos trabalhadores: partidos intitulados de operários [...] sindicatos, greves" (FAUSTO, 1995, p. 299). Em 1917, os trabalhadores brasileiros surpreenderam os patrões e o governo, e o Brasil parou para ver a maior greve já ocorrida até então que, de fato, mostrou a força do proletariado e assustou os detentores do poder. Nesse sentido, Fernanda Barreto Lira explica que:

[...] O Estado de São Paulo teve sua economia completamente paralisada naquele momento. Uma convulsão social sem precedentes apanhava de surpresa o Brasil. Os números revelaram que cem mil trabalhadores cruzaram os braços, em todos os setores produtivos e mesmo na esfera cultural. Todos os espetáculos foram adiados enquanto durasse o movimento. Em alguns casos, os pleitos chegaram a ser atendidos, mas as categorias profissionais mantiveram-se paradas, em solidariedade ao conjunto. (LIRA, 2009, p. 116).

Essa greve inspirou a classe operária a articular mais movimentos de luta, bem como a se reunir em sindicatos, que tentaram se organizar e principalmente se legitimar como representantes dos trabalhadores brasileiros. O crescimento da organização da classe trabalhadora trouxe como uma de suas consequências o aumento da repressão por parte do governo e das elites. Segundo Boris Fausto, "a onda grevista arrefeceu a partir de 1920, seja pela 
dificuldade de alcançar êxitos, seja pela repressão" (FAUSTO, 2006, p. 302). Fábio Campinho explica que "a repressão aos movimentos grevistas esteve presente em toda a República Velha, tendo preponderado na prática a visão do presidente Washington Rodrigues de que o problema social era caso de polícia” (CAMPINHO, 2006, p. 117).

Nos últimos anos da Primeira República surgem algumas normas isoladas que visam a incipiente regulamentação da relação capital-trabalho:

O crescimento do operariado urbano, sua dramática situação e seu potencial explosivo, já não podiam ser totalmente ignorados, o que não significa que tais leis foram realmente cumpridas. O importante é que, apesar de todas as limitações desta legislação, ela representava uma fenda na concepção liberal até então soberana na regulação das relações de trabalho (CAMPINHO, 2006, p. 122)

É necessário atentar-se para o fato de que mesmo com as greves que ocorreram na República Velha, com a criação de leis esparsas e a existência de movimentos e partidos que tentavam arregimentar a classe operária, ou falar em nome dela, trabalhadores e trabalhadoras continuavam em sua grande maioria carentes de direitos e de uma articulação organizada. Essa carência seria um campo fértil, nos anos 1930, para a ação do Estado por meio da política trabalhista de Getúlio Vargas (FAUSTO, 2006). Mas é importante compreender, desde já, que a carência de representação e organização não significa sua inexistência, pois homens e mulheres lutaram muito no início do século XX para que a classe trabalhadora fosse minimamente respeitada na sua relação com o capital. As greves e os movimentos operários e sociais em geral, ainda que atingissem percentual pequeno da incipiente classe trabalhadora urbana, demonstravam a força potencial dos movimentos organizados, o que certamente preocupava as elites dominantes.

Os trabalhadores reivindicavam direitos parecidos com os que vinham sendo garantidos em outros países. Segundo Vito Giannotti (2007, p. 112) entre esses direitos requeriam " 8 horas de trabalho diário, salário-mínimo, descanso semanal, regulamentação do trabalho da mulher e dos menores, previdência social".

A disputaideológica, importante no nascimento do sindicalismo brasileiro, se concentrava principalmente entre anarquistas, comunistas, socialistas e amarelos, esses também chamados (até hoje) de "pelegos" (ALVES, 2015). Para controlar e conter insatisfações tanto da classe trabalhadora quanto dos donos dos meios de produção, Vargas jogava o jogo das marionetes, ao estilo de D. Pedro II no Segundo Reinado, que precisava agradar liberais e conservadores.

A política de Getúlio Vargas na regulamentação do mercado e do trabalho

O governo Vargas foi marcado pela tentativa de construção de uma identidade nacional forte e centralizada, tendo na figura do presidente o protagonista desse novo Brasil, principalmente durante o Estado Novo. 
Há dois pontos que se destacam na política econômica e na regulamentação do mercado durante o governo Vargas: o setor cafeeiro e o setor industrial. Celso Furtado trata da economia de transição para um sistema industrial, em seu clássico "Formação Econômica do Brasil”. A análise específica da transição destaca a crise mundial de 1929, momento em que a exportação de café era artificialmente estimulada pelo Estado brasileiro e mantida em patamares sempre estáveis. Tal política estatal permitiu manter empregos em outros setores da economia (FURTADO, 1974). O problema, entretanto, era que "manter elevado o preço do café de forma persistente era criar condições para que o desequilíbrio entre oferta e procura se aprofundasse cada vez mais" (FURTADO, 1974, p. 182). Na década de 1930, tem início o declínio da produção e das exportações cafeeiras, "que vivia em regime de destruição de um terço do que produzia com um baixo nível de rentabilidade" e que por isso "afugentava desse setor os capitais que nele ainda se formavam." (FURTADO, 1974, p. 197). Houve crescimento da participação econômica de produtos voltados ao mercado interno, o que foi um dos fatores de indução da atividade industrial. Celso Furtado explica:

O crescimento da procura de bens de capital, reflexo da expansão da produção para o mercado interno, e a forte elevação dos preços de importação desses bens, acarretada pela depreciação cambial, criaram condições propícias à instalação no país de uma indústria de bens de capital. (...) A procura de bens de capital cresceu exatamente numa etapa em que as possibilidades de importação eram as mais precárias possíveis (FURTADO, 1974, p. 199).

O governo não abandonou o setor cafeeiro e nem poderia fazê-lo, vez que ele era um dos grandes responsáveis pela sustentação econômica nacional e também por financiar a industrialização do Brasil e, sendo assim, buscou subsidiá-lo (FAUSTO, 2006). Vargas determinou a compra de grande parte do café produzido no Brasil e ordenou a queima de milhões de sacas para controlar ao máximo o preço do produto e fazer com que ele não se desvalorizasse substancialmente no exterior (FAUSTO, 2006). Ocorre que para realizar essa estratégia, o governo emitiu moeda, o que provocou inflação. Essa crise enfrentada pelo Brasil, de início, proporcionou um congelamento na ainda incipiente e frágil atividade industrial, vez que grande parte do dinheiro investido era proveniente dos lucros do setor cafeeiro. Porém, pouco tempo depois, no Estado Novo, ocorreria o desenvolvimento da industrialização do Brasil, baseada em substituição de importações. Segundo Boris Fausto:

A política econômico-financeira do Estado Novo representou uma mudança de orientação relativamente aos anos 1930-1937. Nesse primeiro período, não houve uma linha clara de incentivo ao setor industrial. O governo equilibrou-se entre os diferentes interesses, inclusive agrários, sendo também bastante sensível às pressões externas [...] A partir de novembro de 1937, o Estado embarcou com maior decisão em uma política de substituir importações pela produção interna e de estabelecer uma indústria de base. Os defensores dessa perspectiva ganharam força, tanto pelos problemas críticos do balanço de pagamentos, que vinham desde 1930, como pelos riscos crescentes de uma guerra mundial, que imporia, como realmente impôs, grandes restrições às importações. (FAUSTO, 2006, p. 369-370). 
Vargas, então, iniciou uma política de valorização da industrialização brasileira, de estatização de setores fundamentais para o bom funcionamento da economia nacional e exaltação e exploração dos recursos naturais como minas e quedas de água (FAUSTO, 2006).

A principal consequência justrabalhista em relação ao desenvolvimento da atividade industrial, marcadamente urbana, foi a necessidade de expansão do mercado consumidor interno, o que se deu por meio da consagração de direitos trabalhistas para empregados urbanos. Inicialmente, a legislação trabalhista abarcava apenas trabalhadores urbanos, fruto da regra contida no artigo 7, alíneas "a" e "b" trabalhadores domésticos e rurais. A escolha de Vargas por esse modelo excludente atendia aos anseios da indústria por mercado consumidor interno e não desagradava o setor agroexportador, que não aceitava suportar o ônus decorrente de direitos trabalhistas, que poderiam encarecer seu produto no mercado internacional.

Paralelamente à CLT, o Estado brasileiro manteve os trabalhadores rurais, que na primeira metade do século XX eram maioria da classe trabalhadora, à margem do sistema protetivo. Vargas, então, estabeleceu o poder da norma jurídica heterônoma e cogente no trabalho urbano, mas manteve a influência coronelista para o trabalho rural, que seguiu inconteste durante todo o seu governo. Francisco Weffort (2003, p. 79) lembra que "o novo regime já não é oligárquico, não obstante as oligarquias não tenham sido fundamentalmente afetadas em suas funções de hegemonia social e política nos níveis local e regional”.

Outro grande destaque da política varguista foi a regulamentação dos sindicatos e dos direitos trabalhistas como uma forma de controle da classe trabalhadora, de seus movimentos de resistência e de forçar a "colaboração de classes" (PARANHOS, 1999). Ao regulamentar a relação capital-trabalho, Vargas se apresentou como o político que se preocupou com os trabalhadores, sem, entretanto, negar os interesses dos patrões:

Mal foi empossado na presidência da República, em 3 de novembro de 1930, Getúlio Vargas criou, no dia 26 desse mês, o Ministério do Trabalho, Indústria e Comércio (MTIC), órgão de tremenda importância para a tentativa de dar corpo ao projeto estatal. A contenção da luta de classes em favor da cooperação orgânica entre as classes, e entre estas e o Estado, seria uma divisa ideológica da ação do Governo Vargas, em nome da paz social e da prosperidade da nação (PARANHOS, 1999, p. 85).

Vargas estabeleceu o controle da formação e atuação dos sindicatos no Brasil, que deveriam seguir as diretrizes impostas pelo presidente e se submeter ao poder do Estado. $\mathrm{O}$ sindicato passou a ser constituído como um órgão de colaboração com o poder público, o que

1 Art. $7^{\circ}$ Os preceitos constantes da presente Consolidação salvo quando fôr em cada caso, expressamente determinado em contrário, não se aplicam: a) aos empregados domésticos, assim considerados, de um modo geral, os que prestam serviços de natureza não-econômica à pessoa ou à família, no âmbito residencial destas; b) aos trabalhadores rurais, assim considerados aqueles que, exercendo funções diretamente ligadas à agricultura e à pecuária, não sejam empregados em atividades que, pelos métodos de execução dos respectivos trabalhos ou pela finalidade de suas operações, se classifiquem como industriais ou comerciais; (BRASIL, 1943). 
se sustentava pelo modelo de unicidade sindical adotado. Alguns grupos de trabalhadores tentaram resistir a esse modelo imposto de sindicalismo, que retirava a autonomia de um órgão cuja existência se justificava e se justifica até os dias de hoje na representação de sujeitos hipossuficientes na relação capital-trabalho. As tentativas de resistência foram combatidas, seja pela força policial, seja por estratégias como a seguinte:

Para ter acesso à Justiça do Trabalho, o empregado tinha de ser membro do sindicato. Isso significava, na prática, que, se estivesse fora do sindicato, sua situação seria difícil. Como se dizia na época, "só quem tem ofício tem benefício" - ter ofício significava ter carteira assinada e ser membro de sindicato legal. Era um modo não só de isolar as lideranças mais independentes e agressivas, como de atrair os trabalhadores para a vida sindical. Com o passar do tempo, até os anarquistas tiveram de aderir a esses sindicatos oficiais, embora tentando resistir dentro deles (VIANA, 2013, p. 50).

Em relação aos direitos trabalhistas, o governo Vargas buscou criar uma imagem amigável tanto com a classe trabalhadora quanto com os empregadores. A regulamentação do trabalho foi realizada de maneira estratégica para pacificar a classe trabalhadora, desencorajando-a a realizar movimentos autônomos na busca por direitos. A ideia de conciliação de classes é presente nos discursos de Getúlio Vargas, que nega o conflito e constrói sua imagem populista em torno dessa negativa:

Em uma palavra, na adesão das massas ao populismo tende necessariamente a obscurecer-se a divisão real da sociedade em classes com interesses sociais conflitivos, e a estabelecer-se a idéia do povo (ou da nação) como uma comunidade de interesses solidários. $O$ que é vedado às classes dominadas como tais - reconhecer a dominação das demais classes em situação de crise hegemônica - é permitido aos indivíduos que as compõem pelo "subterfúgio" do reconhecimento das lideranças populistas. (WEFFORT, 2003, p. 178).

Francisco Weffort apresenta caracterização formal do populismo que, embora seja, segundo o autor, insuficiente para abranger todo o fenômeno, é útil para a sua compreensão. Além disso, especificamente para os fins do presente estudo, a caracterização abaixo serve para destacar os papeis de capital e trabalho:

Aí estabelecem-se as seguintes condições gerais para o populismo: 1 - "massificação", provocada pela "proletarização" (de fato, mas não consciente) de amplas camadas de uma sociedade em desenvolvimento que desvincula os indivíduos de seus quadros sociais de origem e os reúne na "massa", "conglomerado multitudinário de indivíduos, relacionados entre si por uma sociabilidade periférica e mecânica"; 2 perda da "representatividade" da "classe dirigente" - e, em con- seqüência, de sua "exemplatidade" - que, assim, se transforma em "dominante", parasitária; 3 - aliadas estas duas condições à presença de um líder dotado de carisma de massas, teríamos todas as possibilidades para o populismo se constituir e alcançar ampla significação social. (WEFFORT, 2003, p. 26). 
O populismo de Vargas, diferente do coronelismo que ainda imperava paralelamente no campo, se desenvolveu nas regiões urbanas nascentes no século XX, marcadas pelo intenso desenvolvimento industrial, como São Paulo (WEFFORT, 2003). Enquanto o coronelismo "expressa um compromisso entre o poder público e o poder privado do grande proprietário de terras, o populismo é, essencialmente, a exaltação do poder público, é o próprio Estado colocando-se por meio do líder, em contato direto com os indivíduos reunidos na massa.” (WEFFORT, 2003, p. 27).

Na prática, e em geral, Getúlio Vargas garantia direitos trabalhistas já reclamados pelos trabalhadores urbanos, e que não confrontariam os interesses dos patrões, e imprimia, nesses direitos, a imagem de uma doação, um presente do Estado a esses sujeitos:

\begin{abstract}
Nessas condições, simultaneamente à legislação social promulgada no Governo Vargas, entra em gestação a ideologia do trabalhismo. O Estado, à sua moda, procuraria apropriar-se da palavra operária, reelaborando-a, tanto quanto possível, ao sabor dos interesses dominantes. O que importa destacar, neste caso, ao contrário do que fazem as interpretações mais simplistas sobre os processos de dominação ideológica, é justamente a influência exercida pelas ideologias dominadas na produção das ideologias dominantes e/ou oficiais. As marcas impressas pelas lutas operárias se tornam bem perceptíveis (PARANHOS, 1999, p. 21).
\end{abstract}

Houve certo consenso histórico, também no âmbito jurídico, no sentido da outorga benevolente de direitos trabalhistas por Getúlio Vargas. O que se pretende demonstrar, em breve análise, é que há uma mistificação em torno dessa ideia, pois a classe trabalhadora brasileira teve papel fundamental na conquista de direitos, o que deveria implicar, também por isso, resistência organizada contra sua perda nos dias de hoje.

O mito da outorga e a participação da classe trabalhadora na construção do Direito do Trabalho

Paira ainda hoje, no estudo das origens do texto da Consolidação das Leis do Trabalho (CLT), o mito da outorga varguista, que apresenta os direitos trabalhistas não só como uma construção exclusiva do presidente e seu governo, mas sobretudo como uma concessão, um verdadeiro presente dado aos trabalhadores. Nas palavras de Márcio Túlio Viana (2013, p. 60), "a CLT nasceu num dia de festa um $1^{\circ}$ de maio. Parecia mesmo um presente. E assim todo um passado de lutas se escondia”.

Evaristo de Moraes Filho destaca como relevante, para a criação de direitos trabalhistas, a mudança de perspectiva sobre a relação capital-trabalho na ordem internacional, que tem no Tratado de Versalhes e na criação da Organização Internacional do Trabalho importantes contribuições. Moraes Filho (1956) cita as principais recomendações do Tratado de Versalhes em matéria trabalhista: o reconhecimento de que trabalho não é mercadoria, direito de associação, 
salário razoável, jornada de 8 horas com limite de 48 horas de disponibilidade semanal de trabalho, repouso semanal, fim do trabalho infantil, igualdade salarial e de tratamento contratual sem discriminações e criação de serviços de inspeção e proteção ao trabalho.

Ao discorrer sobre os primórdios da Consolidação das Leis do Trabalho, Evaristo de Moraes Filho lembra do golpe de Estado perpetrado por Vargas, em 1937, que instituía um "Estado forte, ditatorial, baseado numa organização corporativa" (MORAES FILHO, 1960, p. 319). O citado autor discorre sobre a CLT em seu momento inicial:

A Consolidação foi útil, representa uma grande tarefa e ficará como um dos marcos mais notáveis da história do nosso direito especial. Sistematizou a legislação confusa e contraditória que possuíamos, harmonizou-a, tornou mais fácil o seu conhecimento e aplicação. (MORAES FILHO, 1960, p. 323).

Em relação ao Direito Material do Trabalho, a parte introdutória da CLT em sua origem

compreende as normas sobre o campo de aplicação da Consolidação e as exclusões correspondentes, o conceito de empregadores e seus equiparados, o conceito de grupo econômico consorcial, a definição de empregado, a de serviços efetivo, os princípios da equiparação salarial e da continuidade da relação de emprego", a proteção do trabalho em domicílio, as fontes do direito do trabalho e as regras para a sua interpretação, além da prescrição genérica. (MORAES FILHO, 1960, p. 323).

Sobre as normas especiais de tutela do trabalho, destaca Moraes Filho, no que interessa diretamente ao presente estudo, "Identificação profissional, duração do trabalho, salário-mínimo, férias, higiene e segurança do trabalho" além de "disposições gerais do contrato individual de trabalho, remuneração, alteração, suspensão e interrupção, rescisão, aviso prévio, estabilidade, força maior e distinções especiais." (MORAES FILHO, 1960, p. 324).

Tais direitos foram e são extremamente importantes para toda a classe trabalhadora, ainda mais em um cenário neoliberal como o atual, de precarização e exclusão deliberada de um número cada vez maior de pessoas que vivem do trabalho. Não se nega a importância de Vargas para a classe trabalhadora, vez que ele foi o primeiro grande político a, de fato, reconhecer a relevância desses sujeitos para o desenvolvimento nacional. Entretanto a crítica que este trabalho pretende fazer é em relação à ideia de simples concessão de direitos quando, na verdade, eles foram conquistados por movimentos de trabalhadores ao longo do tempo. Vargas sabia do poder de trabalhadores unidos e bem-organizados e, em razão disso, sempre defendeu uma suposta "conciliação" das classes patrocinada pelo Estado. Segundo Adalberto Paranhos (1999), o que Vargas fazia era, em última análise, roubar a fala dos trabalhadores, reformulá-la e devolver a eles como mito.

A ideia construída e propagada pelo governo varguista foi a de que no Brasil, nos anos 1930, não havia reivindicações dos trabalhadores em matéria de direitos trabalhistas. Veja-se o discurso de Salgado Filho, Ministro do Trabalho do governo Vargas: 
[...] tendes uma legislação que vos foi concedida sem nenhuma exigência, imposição ou pressão de qualquer ordem, mas espontaneamente. E isso é exatamente o que constitui o traço predominante que nos coloca, em matéria de legislação social, acima de todos os países. O que se chama de reivindicações trabalhistas não foram jamais obtidas em qualquer país como estão sendo aqui verificadas. No Brasil não há reivindicações nesse assunto. Há concessões (COSTA, 2013, p. 22).

O mito da outorga, que considera direitos como dádivas, parece ser até mesmo anterior a Vargas. Teresa Sales, em seu artigo intitulado "Raízes da Desigualdade Social na Cultura Política Brasileira”, em uma tentativa de buscar a origem da construção da cidadania do brasileiro, afirma que ela teve sua primeira expressão naquilo que nomeou como "cidadania concedida". Aponta que a cultura da cidadania concedida marcou o povo brasileiro ainda na sociedade escravocrata, quando mesmo "homens livres e pobres" eram inteiramente dependentes dos favores dos senhores de terras, encontrando-se sempre protegidos pelas "sombras de suas dádivas" (SALES, 1994, p. 1). Tal cultura manteve-se dominante na época de fazendas e engenhos coloniais, sobreviveu à abolição da escravatura, ao domínio coronelista e chegou até os dias atuais (SALES, 1994, p. 1). Conceituando e exemplificando a ideia perpetuada de dádivas concedidas aos cidadãos, Teresa Sales explica:

\footnotetext{
Essa cidadania concedida, voltando aos argumentos utilizados no início deste artigo, tem a ver com o próprio sentido da cultura política da dádiva. Os direitos básicos à vida, à liberdade individual, à justiça, à propriedade, ao trabalho; todos os direitos civis, enfim, para o nosso homem livre e pobre que vivia na órbita do domínio territorial, eram direitos que lhe chegavam como uma dádiva do senhor de terras. (SALES, 1994, p. 5)
}

Nota-se, portanto, a perpetuação na sociedade brasileira da ideia de que qualquer direito conquistado sempre foi, na verdade, concedido, outorgado, dado de presente pelos detentores do poder econômico, social e político. Segundo Teresa Sales, tal cultura é marcada por uma relação dialética entre mando e subserviência, ligada diretamente às raízes da desigualdade social no país (SALES, 1994, p. 8). Em tal relação, cada conceito se representa como a face de uma mesma moeda, posto que uma não existe sem a outra. A subserviência dos cidadãos é, certamente, imposta pelo "mando" daqueles que se encontram em posição de poder superior. Desta maneira, quando a relação tende a se desequilibrar, os detentores do "mando" tendem a "conceder" direitos à parte subserviente, não por mera benevolência (como é amplamente divulgado), mas unicamente pelo reestabelecimento da relação dialética de dominação anteriormente constituída (SALES, 1994).

Vargas tentou silenciar ou inibir o associativismo negro, com relativo sucesso. Petrônio Domingues, em verbete no "Dicionário da Escravidão e Liberdade", registra que o Estado Novo "não conseguiu amordaçar tais associações; fez, porém, com que se retraíssem e perdessem parte do potencial reivindicativo. As que sobreviveram - como os clubes e as escolas de samba 
- tinham um caráter mais recreativo ou carnavalesco" (DOMINGUES, 2018, p. 117). Claudma Paiva Carvalho (2017) destaca o protagonismo negro na luta contra a escravidão e estuda suas implicações sociais. Por fim, nesse ponto específico e periférico da análise, é importante afirmar que a classe trabalhadora brasileira não nasce após 1888 , mas se verificam sua existência e atuação bem antes, com a resistência dos negros ao regime escravista (ALVES, 2015). Enfim, a Princesa Isabel não concedeu graciosamente a liberdade dos negros, assim como Getúlio Vargas não deu à classe trabalhadora a legislação trabalhista.

Divulgou-se durante seu governo que Vargas antecipou qualquer reclamação, movimento operário ou greve, numa espécie de premonição genial que culminou na publicação da CLT posteriormente (CAMPANHA; BOSCHI, 2009). Contudo, entre os anos 1930 e 1940, emergiam greves, sobretudo nas grandes cidades, estando os trabalhadores mais do que cientes da importância dos movimentos de resistência como maneira de influenciar a política governamental:

Questiona-se, portanto, que Vargas, de forma "iluminada", captava as necessidades dos trabalhadores sem que estes precisassem dizê-las. Retórica que passaria despercebida não fossem os registros que a própria história tradicional aponta sobre os inúmeros casos de greves que se alastraram na década de trinta, como a de maio de 1932, em São Paulo, e fortemente reprimida; a de 1935 no Rio de Janeiro, e que se alastrou por outras cidades, como Recife (CAMPANA; BOSCHI, 2009, p. 55)

A estratégia adotada pelo governo visava a desconstruir a luta de classes e a organização operária, pretendendo inculcar no inconsciente da população que esses movimentos deveriam ser vistos como agitadores, perturbadores da paz e, além de tudo, desnecessários, pois o que os trabalhadores necessitavam já estaria sendo concedido a eles como um presente do governo (CAMPANA; BOSCHI, 2009). O trabalhador brasileiro, como ser individualizado, de outro lado, deveria ser enxergado como pacífico e conivente com a política governamental, assim como um colaborador para um melhor desenvolvimento da economia.

O Estado, principalmente por meio do Ministério do Trabalho, atuaria juntamente aos sindicatos (patronais e de trabalhadores) como agentes corretivos, retificadores do movimento trabalhista, estabelecendo um diálogo entre o poder público, os empregadores e os trabalhadores (CAMPANA; BOSCHI, 2009). Tamanha foi a propaganda realizada em prol dessa ideia, principalmente através do DIP (Departamento de Imprensa e Propaganda), que a historiografia continuou reproduzindo o discurso varguista como verdadeiro (COSTA, 2013) durante a maior parte do século XX.

Uma exceção à adesão ao mito da outorga veio de Evaristo de Moraes Filho, abaixo citado por John D. French: 
... não houve outorga nenhuma [...] As massas operárias lutaram durante um triênio e ainda lutam hoje e continuarão a lutar - pelo advento de leis que lhes melhorassem as condições de vida. Houve greves, lutas, sangue, desespero, prisões, morte. Como falarse em pobres-diabos, sem líderes, sem idéias, sem aspirações que receberam tudo que se lhes queria dar como favores espontâneos e unilaterais? (MORAES FILHO, apud FRENCH, 2001, p. 84)

Há de se ressaltar, portanto, que embora o discurso do mito da outorga ainda seja propagado até os dias de hoje, a história do Direito do Trabalho no Brasil passa, essencialmente, pela luta dos trabalhadores para conquista de seus direitos. Há notícias de greves mesmo antes da Proclamação da República, como, por exemplo, a greve dos três jornais do Rio de Janeiro, no longínquo ano de 1858, em face das precárias condições de trabalho a que os trabalhadores eram submetidos (COSTA, 2013). Em função de tal movimento, segundo Adailton Pires Costa (2013), nenhum jornal circulou pelas ruas da cidade durante alguns dias.

É relativamente simples, historicamente, reconhecer quais são as outras fontes materiais, além da luta da classe trabalhadora, para a emergência do Direito do Trabalho no Brasil no início do século passado. Magda Barros Biavaschi (2007) relaciona a Encíclica Papal Rerum Novarum, o $1^{\circ}$ Congresso Brasileiro de Direito Social, e diversas constituições sociais do início do século XX, além de Convenções Internacionais da OIT. Percebe-se, portanto, que de outorga pouco há na legislação trabalhista brasileira. O que há, de fato, é a luta operária, nacional e internacional, que culminou em respostas capitalistas, e até mesmo religiosas, no sentido do reconhecimento de direitos trabalhistas. Não há dádiva, mas conquistas. Importante, neste sentido, compreender o papel dos trabalhadores na construção dos seus direitos para que se reflita sobre sua relevância na preservação daquilo que foi duramente conquistado e que se encontra agora ameaçado tanto pelo capital quanto pelo Estado.

\section{Destruição do direito do trabalho no século XXI: legislação trabalhista neoliberal no Brasil}

Nunca antes no Brasil, a classe trabalhadora se viu tão pressionada em relação às suas conquistas históricas quanto neste início de século. Nem mesmo a ditadura civil-militar, inaugurada em 1964, ameaçou ou agrediu tanto os direitos trabalhistas no país quanto o que se vê agora. O contexto atual de agressão à legislação trabalhista é fundamentado no neoliberalismo, que assola boa parte do mundo capitalista desde a década de 70 do século passado. Ao presente estudo interessa o neoliberalismo enquanto ausência do Estado nas relações intersubjetivas, dentre elas a relação de emprego. A ideia básica, implementada em diversos países, é reduzir o papel do Estado na regulamentação da relação capital-trabalho e, paralelamente, diminuir também a relevância do sindicato dos trabalhadores enquanto sujeito coletivo obreiro. A estratégia é criar o discurso da "modernização trabalhista", posto que a CLT seria anacrônica, o que resulta agora na destruição da proteção normativa heterônoma estatal, intensificada pela pandemia do coronavírus. 
O discurso da "modernização trabalhista" pelos detentores

do poder político no Brasil pós-2016

A tomada do poder por Michel Temer, em 2016, potencializa um discurso, recorrente, de fim da herança varguista caracterizada pela Consolidação das Leis do Trabalho e início da modernização das relações trabalhistas. Uma das primeiras reuniões públicas de Temer durante o processo de impeachment da Presidenta Dilma Rousseff foi com a Confederação Nacional da Indústria $(\mathrm{CNI})$, oportunidade em que ouviu vários de seus pleitos e críticas:

O presidente da Confederação Nacional da Indústria (CNI), Robson Braga, afirmou nesta terça-feira (16), após se reunir com o presidente da República em exercício Michel Temer, que a entidade pediu ao governo mudanças na legislação trabalhista. Integrantes do governo têm dito que pretendem enviar uma proposta de reforma ao Congresso ainda neste ano. Em julho, também após se reunir com Temer, o presidente da CNI já havia defendido que o Brasil deveria "estar aberto a mudanças" na legislação trabalhista para enfrentar a crise econômica. Ele citou o exemplo da França, onde o governo adotou uma reforma trabalhista que permite, entre outras medidas, que empresas negociem com empregados o aumento da jornada para até 60 horas semanais, em casos excepcionais. (MATOSO, 2016, n.p.).

O pedido da CNI foi concretizado quase que integralmente (ALVES, 2015; ALVES, ALVES, 2017) e pouco antes da entrada em vigor do texto da "Reforma Trabalhista" Michel Temer parece ter se apropriado da estratégia de Getúlio Vargas para tentar convencer a classe trabalhadora das vantagens de uma mudança na legislação:

A cerca de mês da entrada em vigor da polêmica reforma trabalhista, o presidente Michel Temer afirmou nesta quarta-feira (4) que o trabalhador e o empresário estão se unindo no país. "De um lado o trabalhador e de outro lado o empresário têm que fazer o que estão fazendo recentemente, se unindo, se unificando", afirmou o presidente em discurso no Palácio do Planalto. (BOLDRINI; ALEGRETTI, 2017, n.p.).

Ora, fácil hoje identificar que o discurso presidencial nada teve de verdade. Naquele momento não havia, e hoje também não há, essa ideia de união, e muito menos unificação, dos interesses de capital e trabalho em torno de mudanças na legislação trabalhista. O patrão tem se mostrado ávido pelas mudanças prejudiciais ao trabalhador, que infelizmente não consegue resistir a contento, por enquanto. $\mathrm{O}$ que há, de fato, é a implementação de um receituário neoliberal que preconiza o individualismo do trabalhador, que majoritariamente tem de se abster da participação sindical para preservar seu emprego, bem como mostrar-se dócil diante do empregador, por saber dos riscos do desemprego, além de lutar sozinho para manter seu contrato e minimamente seus direitos, pois o Estado cada vez mais age contra a preservação da legislação protetiva. 
Várias foram as manifestações de deputados e senadores quando da tramitação do texto da Reforma Trabalhista no Congresso Nacional a respeito da "herança varguista", aqui representadas pelo relatório final do então deputado Rogério Marinho, que relacionava a CLT não só a Getúlio Vargas e ao Estado Novo, mas também ao fascismo do governo italiano de Mussolini:

O Brasil de 1943 não é o Brasil de 2017. Há 74 anos éramos um país rural, com mais de $60 \%$ da população no campo. Iniciando um processo de industrialização, vivíamos na ditadura do Estado Novo, apesar disso, o governo outorgou uma legislação trabalhista que preparava o país para o futuro. Uma legislação que regulamentava as necessidades do seu tempo, de forma a garantir os patamares mínimos de dignidade e respeito ao trabalhador. (...) Novas profissões surgiram e outras desapareceram, e as leis trabalhistas permanecem as mesmas. Inspiradas no fascismo de Mussolini, as regras da CLT foram pensadas para um Estado hipertrofiado, intromissivo, que tinha como diretriz a tutela exacerbada das pessoas e a invasão dos seus íntimos. (BRASIL, 2017, n.p.).

Um ano após a Reforma Trabalhista, mesmo sem ter de fato nada a comemorar, o exdeputado (não reeleito em 2018), e atual ministro do governo Bolsonaro, Rogério Marinho, festejava no Twitter:

Após um ano constatamos que a herança peleguista da república sindical de Vargas começa a ruir, em 2018 a contribuição sindical que era obrigatória e passou a ser opcional foi reduzida em $86 \%$. Agora sindicatos terão de ser relevantes e prestar serviços ou desaparecerão. (MARINHO, 2018, n.p).

É verdade que os sindicatos foram afetados, o que aliás está em consonância com um dos pilares iniciais do neoliberalismo inglês, sob Margaret Tatcher, na década de 1970. Em sentido contrário à comemoração do relator do texto, empregados e empregadores não têm o que comemorar. Hoje já é possível perceber que a Reforma Trabalhista de 2017 (leis 13.429 e 13.467 de 2017) não trouxe novos empregos, não diminuiu o desemprego (ao contrário) e não melhorou a vida da classe trabalhadora. Sequer melhorou acentuadamente as possibilidades fáticas de contratação pelo empregador. Prova disso é a profusão de reformas que sucederam e sucederão à primeira, sempre como o mesmo falacioso discurso, que agora volta à pauta.

A continuação da reforma trabalhista, agora sob Bolsonaro, se iniciou com o "Contrato de Trabalho Verde e Amarelo", e também foi comemorada pela CNI com o mesmo discurso de "modernização", ou seja, como ruptura com o passado celetista. Trata-se, também, de uma proposta normativa de ideologia neoliberal, pois deixa para as partes contratantes boa parte dos conteúdos mínimos de regulação da relação. Para a CNI, o novo contrato seria a continuidade "daquilo que temos chamado de modernização das leis trabalhistas e caminha no sentido do nosso desenvolvimento econômico. Estamos a tratar de uma nova modalidade que visa inserir jovens no mercado de trabalho, do qual hoje eles estão alijados" (ABREU, 2020, n.p.). As medidas 
reformistas seguintes de Bolsonaro são emergenciais, no contexto da pandemia do coronavírus, mas também foram comemoradas como modernização das relações de trabalho.

Destruição da proteção normativa heterônoma estatal pós-2016 e a pandemia do coronavírus

O início do século XXI será crucial para os destinos do Direito do Trabalho no Brasil e no mundo, sobretudo após a pandemia do novo coronavírus. Ao presente artigo interessam as estratégias do Estado brasileiro após 2017 na definição das novas normas de regulamentação da relação capital-trabalho, com destaque para o disposto nas leis 13.429/2017, 13.467/2017, 13.874/2019, MPV 905/2019, MPV 927/2020 e MPV 936/2020. ${ }^{2}$ Todas essas alterações podem ser compreendidas como parte do processo amplo de Reforma Trabalhista inaugurado pela legislação de 2017 no governo Temer e que infelizmente segue se aprofundando nos dias atuais.

Para os fins do presente artigo, o essencial é compreender brevemente os caminhos do Estado brasileiro ao patrocinar as propostas de mudança legislativa. A intenção neoliberal do governo Temer foi totalmente implementada no início da Reforma Trabalhista, em 2017, conforme fixado nas leis 13.429 e 13.467. Em seguida, com impacto menos intenso nos direitos individuais trabalhistas, foi editada a Lei 13.874/2019, denominada "Lei de Liberdade Econômica", já no governo Bolsonaro, que tem parte de seu conteúdo voltado a alterações na CLT. Embora não tenha sido implementado em um primeiro momento, provavelmente o "Contrato de Trabalho Verde e Amarelo" voltará à discussão no Congresso Nacional. Além dessas amplas medidas de redução de direitos trabalhistas, houve opção pela edição de medidas provisórias para fazer face aos efeitos da pandemia do coronavírus. Embora a aplicação das medidas de redução de direitos durante a pandemia seja "transitória", ela reflete bem as escolhas do Estado brasileiro em sua linha de atuação neoliberal.

Para retratar esse momento de mudança nos rumos da legislação trabalhista, segue o Quadro 1. A opção, até mesmo em razão do número enorme de temas, institutos e direitos trabalhistas impactados, foi por restringir a análise ao que é o centro do Direito Individual do Trabalho: duração do trabalho, remuneração e contrato.

2 Em relação às medidas provisórias, independentemente de alteração, rejeição ou aprovação pelo Congresso Nacional (o Executivo encontra grandes dificuldades de aprovação de MPV's, graças à sua dificuldade de diálogo democrático), importante será compreender o que o governo Bolsonaro pretende para as relações capital-trabalho. 
Quadro 1 - Alteração da Legislação Trabalhista - 12/2017 a 05/2020

\begin{tabular}{|c|c|c|c|}
\hline Alteração: redução de direitos & Tema & $\begin{array}{r}\text { Norma } \\
\text { Impactada }\end{array}$ & $\begin{array}{r}\text { Referência } \\
\text { da alteração }\end{array}$ \\
\hline Tempo à disposição & Duração do trabalho & CLT, art. $4^{\circ}$. & Lei $13.467 / 2017$ \\
\hline Deslocamento interno & Duração do trabalho & CLT, art. 58 & Lei $13.467 / 2017$ \\
\hline Compensação de jornada & Duração do trabalho & CLT, art. 59 & Lei $13.467 / 2017$ \\
\hline $12 \times 36$ sem intervalo & Duração do trabalho & CLT, art. 59 & Lei $13.467 / 2017$ \\
\hline Pagamento parcial de intervalo & Duração do trabalho & CLT, art. 71 & Lei $13.467 / 2017$ \\
\hline Intervalo de 30 minutos & Duração do trabalho & CLT, art. 71 & Lei $13.467 / 2017$ \\
\hline Horas in itinere & Duração do trabalho & CLT, art. 58 & Lei $13.467 / 2017$ \\
\hline Banco de Horas & Duração do trabalho & CLT, art. 59 & Lei $13.467 / 2017$ \\
\hline Jornada em ambiente insalubre & Duração do trabalho & CLT, art. 60 & Lei $13.467 / 2017$ \\
\hline Fracionamento das férias & Duração do trabalho & CLT, art. 134 & Lei $13.467 / 2017$ \\
\hline Regime de tempo parcial & Remuneração & CLT, art. 58-A & Lei $13.467 / 2017$ \\
\hline Teletrabalho sem horas extras & Remuneração & CLT, art. 62 & Lei $13.467 / 2017$ \\
\hline Prêmios sem natureza remuneratória & Remuneração & CLT, art. 457 & Lei $13.467 / 2017$ \\
\hline Exclusão de natureza remuneratória & Remuneração & CLT, art. 457 & Lei $13.467 / 2017$ \\
\hline Exclusão de gratificação de função & Remuneração & CLT, art. 468 & Lei $13.467 / 2017$ \\
\hline Equiparação, PCS e homologação & Remuneração & CLT, art. 461 & Lei $13.467 / 2017$ \\
\hline Logomarcas em uniformes & Remuneração & - & Lei $13.467 / 2017$ \\
\hline $\begin{array}{l}\text { Termo de quitação anual de } \\
\text { obrigações trabalhistas }\end{array}$ & Remuneração & - & Lei $13.467 / 2017$ \\
\hline
\end{tabular}


Contratação formal de autônomo

Trabalho intermitente

Livre negociação "hipersuficiência"

Terceirização irrestrita

Fim do ponto eletrônico

Registro do ponto por exceção

Ampliação do prazo de registro de CTPS

“Direitos rescisórios" pagos mensalmente

Redução de alíquota FGTS para 2\%

Inaplicabilidade de multa por rescisão antecipada do contrato a termo

Liberação de trabalho aos domingos sem ônus e de modo irrestrito

Trabalho dos bancários aos sábados

Ampliação da duração do trabalho dos jornalistas

Fim da natureza salarial da alimentação

Cobrança de INSS s/ Seguro

Desemprego

Trabalho dos professores aos domingos

\section{Contrato}

Lei $13.467 / 2017$

Contrato

Lei $13.467 / 2017$

Contrato

Lei 13.467/2017

Contrato

Lei 6.494/1974

Lei 13.429/2017

Lei $13.467 / 2017$

Duração do trabalho

CLT, art. 74

Lei $13.874 / 2019$

Duração do trabalho

CLT, art. 74

Lei 13.874/2019

Contrato

CLT, art. 29

Lei $13.874 / 2019$

Remuneração

CLT, art. 477

MPV 905/2019

Remuneração ADCT/CR 10, I.

MPV 905/2019

Remuneração

CLT, art. 479

MPV 905/2019

Duração do trabalho

Lei 605/1949

MPV 905/2019

Duração do trabalho

CLT, art. 224

MPV 905/2019

Duração do trabalho

CLT, art. 304

MPV 905/2019

Remuneração

CLT, art. 458

MPV 905/2019

Remuneração

Lei 8.212/1991

MPV 905/2019

Duração do trabalho

CLT, art. 319

MPV 905/2019 
Exclusão do acidente de percurso como acidente de trabalho e consequente garantia provisória de Contrato Lei 8.213/1991 MPV 905/2019 emprego

Acordo individual de trabalho com preponderância sobre a lei, ACT, CCT.

Contrato $\mathrm{CR}, \operatorname{art.} 7^{\circ}$, XXVI

MPV 927/2020

Suspensão de exigências administrativas em segurança e saúde no trabalho

Implementação de teletrabalho independentemente de restrições contratuais, de ACT ou CCT

Antecipação de férias sem implementação de período aquisitivo

Duração do trabalho

Duração do trabalho

Duração do trabalho

CLT, art. 134

MPV 927/2020 serviços essenciais

Conversão de $1 / 3$ de férias como opção do empregador

Desnecessidade de antecipação dos valores referentes às férias

Remuneração

CLT, art. 145

MPV 927/2020

Duração do trabalho

Lei 605/1949

MPV 927/2020

Ampliação dos prazos máximos do

Banco de Horas

Afastamento do empregado para qualificação, sem pagamentos ${ }^{3}$

Flexibilização de jornada e períodos de descanso dos trabalhadores da área da saúde
Duração do trabalho

Remuneração

Duração do trabalho
CLT, art. 59

MPV 927/2020

CR, art. $7^{\circ}$, IV

e VI

MPV 927/2020

MPV 927/2020 
Desconsidera a COVID-19 como doença profissional, o que pode afastar Contrato Lei 8.213/1991 MPV 927/2020 a garantia provisória de emprego ${ }^{4}$

Redução de jornada e de salário sem negociação coletiva

Remuneração CR, art. 7º, VI MPV 936/2020

Suspensão do contrato de trabalho sem salário integral, mas com benefícios governamentais, ainda que Remuneração CR, art. 7º, VI MPV 936/2020 parciais

Fonte: elaborado pelos autores no âmbito do Grupo de Estudos Jurídicos COVID-19 da UFOP.

Esse rol significativo, com cinquenta medidas legislativas de redução de direitos, trata somente de três temas, como visto: duração do trabalho, remuneração e contrato. É apenas uma parte da estrutura de Direito Individual do Trabalho e as alterações aqui relacionadas representam parcialmente as perdas suportadas pela classe trabalhadora desde 2017. Há muitos outros direitos trabalhistas afetados nos últimos anos, seja em matéria de direito individual, coletivo, processual ou administrativo do trabalho, o que desafia a classe trabalhadora à luta pela reversão desse quadro caótico e pela proteção das suas conquistas sociais históricas, que, afinal, não foram uma benesse do Estado, mas, sim, fruto de muitas lutas.

\section{Considerações finais}

O que se pretendeu aqui demonstrar, portanto, é que as conquistas históricas da classe trabalhadora não deveriam ser objeto de alteração estatal sem que haja qualquer contrapartida para os empregados. Atuar somente em prol do patrão significa promover muito mais do que alteração legislativa, pois resulta em agressão às garantias sociais construídas historicamente e também em ruptura do equilíbrio sistêmico até então havido entre patrões e empregados no plano do Direito do Trabalho. A partir do momento em que patrões e Estado se desobrigam daquilo que consolidaram historicamente, a classe trabalhadora também pode e deve romper com o imobilismo e lutar ativamente pela preservação de suas conquistas, forçando ambos a rever seu posicionamento e a recompor as perdas até aqui experimentadas. Não houve dádiva estatal na construção dos direitos trabalhistas e, consequentemente, sua supressão não deveria ser imposta em prejuízo do interesse da maioria.

4 Eficácia suspensa pelo STF em sede de ADIs 6375 e 6377. 


\section{Referências}

ABREU, Diego. Contrato Verde e Amarelo dá continuidade à modernização das leis trabalhistas. Portal da Indústria, Brasília, DF, 12 fev. 2020. Disponível em: https://conexaotrabalho.portaldaindustria.com.br/noticias/ detalhe/trabalhista/modernizacao-e-desburocratizacao-trabalhista/contrato-verde-e-amarelo-da-continuidademodernizacao-das-leis-trabalhistas/ Acesso em: 04 ago. 2020

ALVES, Amauri Cesar; ALVES, Roberto das Graças. Reforma Trabalhista e o Novo "Direito do Capital”. Revista Síntese Trabalhista e Previdenciária, v. XXIX, p. 47-74, 2017.

ALVES, Amauri Cesar. Pluralidade Sindical: nova interpretação constitucional e celetista. São Paulo: LTr., 2015. BIAVASCHI, Magda Barros. O Direito do Trabalho no Brasil 1930-1942: a construção do sujeito de direitos trabalhistas. São Paulo: LTr., 2007.

BOLDRINI, Angela; ALEGRETTI, Laís. Em evento, Temer diz que trabalhador e empresário estão se unindo no país. Folha de São Paulo, São Paulo, 4 out. 2017. Disponível em: https://www1.folha.uol.com.br/mercado/27/10/1924209em-agenda-positiva-temer-anuncia-medidas-para-pequenas-empresas.shtml Acesso em: 04 ago. 2020.

BRASIL. Decreto-lei n. 5.452, de $1^{\circ}$ de maio de 1943. Aprova a Consolidação das leis do Trabalho. Disponível em: http://www.planalto.gov.br/ccivil_03/decreto-lei/del5452.htm Acesso em: 04 ago. 2020.

BRASIL. Projeto de Lei 6787/2016. Brasília, DF: Câmara dos Deputados, 12 abr. 2017. Disponível em: https://www. camara.leg.br/proposicoesWeb/prop_mostrarintegra;jsessionid=FFCEE74FD4BCBA0ABFB111F1CF3B3277.pro posicoesWebExterno2? codteor=1544961\&filename=Tramitacao-PL+6787/2016 Acesso em: 10 abr. 2020.

CAMPANA, Prisicila; BOSCHI, Olga Maria. A falácia do discurso da doação das leis trabalhistas: Recuperando outras memórias históricas. Revista de Informação Legislativa, Brasília, v. 46, n. 181, p. 53-70, jan./, mar. 2009. Disponível em: https://www2.senado.leg.br/bdsf/bitstream/handle/id/194893/000861667.pdf? sequence=3\&isAllowed=y. Acesso em: 4 nov. 2019.

CAMPINHO, Fábio. Sindicalismo de estado: controle e repressão na Era Vargas (1930-1935). Revista Eletrônica do CEJUR, Curitiba, v. 1, n. 1, p. 114-135, ago./dez. 2006. Disponível em: <https://revistas.ufpr.br/cejur/article/ view/14838>. Acesso em: 5 nov. 2019.

CARVALHO, Claudma Paiva. BRASIL 1880-1888: o protagonismo dos negros na luta contra o sistema escravista e suas implicações sociais. In: MARQUES, Ana Carolina Bianchi Rocha Cuevas; SOUTO MAIOR, Giovanna Maria Magalhães; RODRIGUES, Renata do Nascimento (org.). Retalhos Históricos do Direito do Trabalho. São Paulo: LTr., 2017. p. 67-74.

COSTA, Adailton Pires. A história dos direitos trabalhistas vista a partir de baixo: a luta por direitos (e leis) dos trabalhadores em hotéis, restaurantes, cafés e bares no Rio de Janeiro da 1a República (DF, 1917-18). 2013. 321 f. Dissertação (Mestrado em Direito) - Programa de Pós-Graduação em Direito, Universidade Federal de Santa Catarina, Florianópolis, 2013. Disponível em: https://core.ac.uk/download/pdf/30384121.pdf. Acesso em: 5 nov. 2019.

DOMINGUES, Petrônio. Associativismo negro. In: SCWARCZ, Lilia M.; GOMES, Flávio (org.). Dicionário da Escravidão e Liberdade. São Paulo: Companhia das Letras, 2018. p. 117-124.

FAUSTO, Boris. História do Brasil. 2 ed. São Paulo: Editora da Universidade de São Paulo, 1995.

FAUSTO, Boris. História do Brasil. 12 ed. São Paulo: Editora da Universidade de São Paulo, 2006.

FRENCH, John D. Afogados em leis: a CLT e a cultura política dos trabalhadores brasileiros. São Paulo: Fundação Perseu Abramo, 2001.

FURTADO, Celso. Formação Econômica do Brasil. 12. ed. São Paulo: Editora Nacional, 1974.

GIANNOTTI, Vito. História das lutas dos trabalhadores no Brasil. Rio de Janeiro: Mauad X, 2007. 
LIRA, Fernanda Barreto. A greve e os novos movimentos sociais: para além da dogmática jurídica e da doutrina da OIT. São Paulo: LTr., 2009.

MARINHO, Rogério. Após um ano constatamos que a herança peleguista da república sindical de Vargas começa a ruir, em 2018 a contribuição sindical que era obrigatória e passou a ser opcional foi reduzida em 86\%. Natal, 11 nov. 2018. Twitter: @rogeriosmarinho. Disponível em: http://twitter.com/rogeriosmarinho. Acesso em: 10 abr. 2020.

MATOSO, Filipe. CNI se reúne com Temer e pede mudanças na legislação trabalhista. G1, Brasília, 16 ago. 2016. Disponível em: http:/g1.globo.com/economia/noticia/2016/08/cni-se-reune-com-temer-e-pede-mudancas-nalegislacao-trabalhista.html. Acesso em: 04 ago. 2020.

MORAES FILHO, Evaristo de. Introdução ao Direito do Trabalho. Rio de Janeiro: Forense, 1956.

MORAES FILHO, Evaristo de. Tratado Elementar de Direito do Trabalho. Rio de Janeiro: Freitas Bastos, 1960.

PARANHOS, Adalberto. O roubo da fala: origens da ideologia do trabalhismo no Brasil. São Paulo: Boitempo, 1999.

SALES, Teresa. Raízes da desigualdade social na cultura política brasileira. Revista Brasileira de Ciências Sociais, São Paulo, v. 9, n. 25, p. 1-11, jun. 1994. Disponível em: <http://www.anpocs.com/images/stories/RBCS/25/ rbcs25_02.pdf>. Acesso em: 19 jul. 2020.

VIANA, Márcio Túlio. 70 anos de CLT: uma história de trabalhadores. Brasília: Tribunal Superior do Trabalho, 2013.

WEFFORT, Francisco C. O populismo na política brasileira. 5. ed. Rio de Janeiro: Paz e Terra, 2003.

Recebido em 15/06/2020

Aceito em 24/07/2020 